Review

\title{
MENINGOCOCCAL MENINGITIS: BACTERIOLOGICAL AND MOLECULAR ASPECTS
}

\author{
G. Lazarova*, M. Teneva, H. Djeneva \\ Department of Microbiology, Medical Faculty, Trakia University, Stara Zagora, Bulgaria
}

\begin{abstract}
Meningococcal disease is a severe illness with high mortality. The etiological diagnosis and early antibacterial therapy are the most important factors for the survival of patients.

This study offers an algorithm for diagnosis and therapy of meningococcal disease, including: samples collection, storage; incubation; biochemical identification; serogrouping and serosubtyping and antimicrobial susceptibility testing, on isolates.
\end{abstract}

Key words: $N$. meningitidis, serogrouping, serosubtyping, RT-PCR, antimicrobial susceptibility testing.

\section{INTRODUCTION}

Meningococcal disease, as meningococcal meningitis and meningococcal sepsis, is a severe bacterial invasive infection, which needs urgent diagnosis and correct antibacterial therapy. In Bulgaria, there is no diagnostic consensus on meningococcal infections, probably because of lack of Reference laboratory for Neisseria.

In this study we offer a diagnostic and therapeutic criteria for IBD (invasive bacterial diseases), specially for meningococcal.

\section{ALGORYTHM FOR MICROBIOLOGICAL DIAGNOSIS}

\section{Sample collection and storage:}

The classical scheme for receipt of strains includes:

The Reference Center for Meningococci- who receives the strains, isolated and identified up to the serogroup. The delivery of the strains is carried out on a special transport-medium (VDK), on which the $N$. meningitidis can remain viable up to 2 weeks.

The unwrapping of the parcel takes place only at the places designated for the purpose.

\footnotetext{
*Correspondence to: Grozdanka T. Lazarova, Dept. of Microbiology, Medical Faculty, Trakia University, Stara Zagora, phone 0888425432, E-mail:

g_lazarova@yahoo.com
}

The shipments should meet the established requirements for safety of microbiological materials (1).

2. Preliminary incubation of strains on transport media at $37^{\circ} \mathrm{C}$ overnight.

3. Isolation of strains on selective media: $\mathrm{GCB}$ (G2) or GCB+VCF (V2)

The culture is made using the four-quadrant technique with one-time inoculating loops. One inoculating tube is taken from the transport media and is cultivated in $\mathrm{G} 2$ or $\mathrm{V} 2$ medium.

It allows the receipt of single colonies in the last quadrant and verification of cultures' purity, colonies type, presence of pigment etc.

4. Incubation of cultures at least $16 \mathrm{hrs}$. at 37 $\mathrm{C}+5 \% \mathrm{CO} 2$ and high humidity.

5. Reading cultures: Follow the principle of 4 +: Lack of growth $=0$; Growth only is 1 quadrant $=1$; Growth in 2 quadrant $=2$; Growth in 3 quadrant $=3$; Growth in 4 quadrant $=4$

In case there is no growth we repeat the procedure from the transport media.

$N$. meningitidis on GCB media has the following morphological characteristics: colonies with smooth, regular edges, 1-1.5 mm, transparent. They 
could be with mucoid consistency, sometimes with greyish pigment.

6. Gram stain from the transport media: smear; fixation; - Gentian violet - 1 min.; flushing with water; Lugol's solution - 1 min.; flushing with water; flushing with acetone-alcohol - 1 min.; flushing with water; Ziehl's carbon fuchsine -1 min.; final flushing with water

\section{Presumptive identification tests:}

\section{Catalase test}

Oxidase test. For the detection of oxidase, reagent discs are used. They are wetted with distilled water. A few colonies are rubbed in on the disc. The presence of dark-purple pigment in 5-10 seconds is considered positive (+) reaction.

\section{Biochemical identification:}

A/ Short biochemical test row: When the bacteria looks like Gram (-) diplococci of the Gram stain, show oxidase and catalase positive test $(+)$ and grow on selective media V2, the following tests are used:

- Petri dish with media HIA (Heart Infusion Agar) - to inspect the growth condition on normal culture media and possible agglutination of meningococci.

- 5 test tubes with CTA medium, containing $1 \%$ final concentration of: glucose, maltose, levulose, sucrose and lactose.

- 2 test tubes Mueller - Hinton slant agar (for possible subsequent agglutination)

- Medium with high content of sucrose (to inspect the synthesis of polysaccharides) - petri dish.
LAZAROVA G., et al.

- Medium to prove Gamma glutamyl transferase $-\gamma$ GT

\section{B/ Full biochemical test row:}

If the bacteria seem like Gram negative (-) diplococci, oxidase and catalase positive (+), but do not grow in selective medium V2 to the ones in the middle of the short row (except for MuellerHinton) additionally are added:

- Medium for reduction of nitrates (liquid and solid)

- Medium for reduction of nitrites (liquid and solid).

- Medium with tributirine (for tributirine hydrolisis)

Cultivation technique: A culture on one whole petri dish HIA, MH ,SA from the culture with G2 medium. For the CTA test tubes the upper $5 \mathrm{~mm}$ are cultivated, as the acidification of the medium is carried out in aerobic medium. Make a suspension of the culture in the test tube for $\boldsymbol{\gamma}$-GT.Cultivate the medium containing tributirine, as well as broths, for row of nitrate and nitrites.Cultivate the media for nitrates and nitrites and cover them with liquid paraffin.

Conditions for cultivation:

Do not cover completely the metal taps of the test tubes in order to meet the requirement for aerobiosis!! Incubate the rows 1 night at $=37 \mathrm{C}$ without CO2!!! (in order to avoid the acidification of the carbon hydrates under the influence of $\mathrm{CO} 2$ ).

Table 1. Interpretation of the results from the biochemical tests:

Biochemical short sheme

\begin{tabular}{|l|c|c|c|c|c|c|c|c|}
\hline & HIA & Glucose & Maltose & Levulose & Saccharose & Lactose & SA & GGT \\
\hline N. meningitidis & + & + & + & - & - & - & - & + \\
\hline N. gonorrhoeae & $+/-$ & + & - & - & - & - & - & - \\
\hline N. lactamica & + & + & + & - & $+/-$ & - & + & - \\
\hline N. polysaccharea & + & + & + & - & $+/-$ & - & + & - \\
\hline
\end{tabular}

Complete biochemical sheme

\begin{tabular}{|l|c|c|c|c|c|c|c|c|c|c|}
\hline & $\begin{array}{c}\text { Glucos } \\
\mathbf{e}\end{array}$ & Maltose & $\begin{array}{c}\text { Levulos } \\
\mathbf{e}\end{array}$ & $\begin{array}{c}\text { Saccharos } \\
\mathbf{e}\end{array}$ & $\begin{array}{c}\text { Lactos } \\
\mathbf{e}\end{array}$ & $\begin{array}{c}\text { SA } \\
\text { GG } \\
\mathbf{T}\end{array}$ & $\begin{array}{c}\text { NO } \\
\mathbf{3}\end{array}$ & $\begin{array}{c}\text { NO } \\
2\end{array}$ & $\begin{array}{c}\text { TR } \\
\text { I }\end{array}$ \\
\hline sicca subflava & + & + & + & + & - & + & + & - & + & - \\
\hline N. flava & + & + & - & - & - & - & + & - & + & - \\
\hline N.per flava & + & + & + & - & - & - & + & - & + & - \\
\hline N. mucosa & + & + & + & + & - & + & $+/-$ & - & + & - \\
\hline N. cinerea & + & + & + & + & - & + & + & + & + & - \\
\hline N. flavescens & - & - & - & - & - & - & - & - & + & - \\
\hline N. denitrificans & + & - & + & + & - & + & - & - & + & - \\
\hline N. canis & $+/-$ & - & - & - & - & - & - & + & - & - \\
\hline N. macacae & + & + & + & + & - & + & + & - & + & - \\
\hline
\end{tabular}




\section{Antimicrobial susceptibility testing:}

For the AST it is recommended Mueller-Hinton with blood (sheep) agar medium, as well as strips E-test to determine the Minimum Inhibitory Concentration (MIC) of: Amoxicillin, Cefotaxime, Chloramphenicol, Rifampicin, Ciprofloxacin and Ceftriaxone.

Disk-diffusion-method (DDM) is not recommended for antimicrobial susceptibility testing of meningococci.
Technique: Prepare $3 \mathrm{mg}$ suspension of the strain in a phosphate buffer. Adjust the suspension to McFarland turbidity Standard = 0.5. The suspension is made with a tampon, soaked in the suspension by rotating the rectangular petri dish 3 - time at $90^{\circ}$. The Etest strip is placed with sterile tweezers.

They are incubated $24 \mathrm{hrs}$. at $37^{\circ} \mathrm{C}$ with $+\mathbf{5 \%}$ CO2! (2).

Reading MIC, using E- test strips, according the scheme of breakpoints for meningococci.

Table 2. There is a big variety of recommended MIC breakpoints for N. meningitidis

(J. Vazkuez. FEMS Microbiol. Rev. 32, 2007, 97-100)

\begin{tabular}{|c|c|c|c|c|}
\hline & & \multicolumn{3}{|c|}{ MIC breakpointe $\left(\mathrm{mgL}^{-1}\right)$} \\
\hline Antibiotic & Organisation & $\mathbf{R} \geq$ & I & $\mathbf{S} \leq$ \\
\hline Sulfisozazole & $\begin{array}{l}\text { CSLI/NCCLS } \\
\text { EMGM working group } \\
\text { Range of breakpoints }\end{array}$ & $\begin{array}{l}8 \\
8\end{array}$ & $\begin{array}{c}4 \\
2-4\end{array}$ & $\begin{array}{l}2 \\
1\end{array}$ \\
\hline Rifampicin & $\begin{array}{l}\text { CSLI/NCCLS } \\
\text { EMGM working group } \\
\text { Range of breakpoints }\end{array}$ & $\begin{array}{c}2 \\
2 \\
1-7 \\
\end{array}$ & $\begin{array}{c}1 \\
0.5-1\end{array}$ & $\begin{array}{c}0.5 \\
0.25 \\
0.25-4 \\
\end{array}$ \\
\hline Ciprofloxacin & $\begin{array}{l}\text { CSLI/NCCLS } \\
\text { EMGM working group } \\
\text { Range of breakpoints }\end{array}$ & $\begin{array}{c}0.12 \\
0.5 \\
0.06-2 \\
\end{array}$ & $\begin{array}{c}0.06 \\
0.06-0.25\end{array}$ & $\begin{array}{c}0.03 \\
0.03 \\
0.03-1 \\
\end{array}$ \\
\hline Penicillin & $\begin{array}{l}\text { CSLI/NCCLS } \\
\text { EMGM working group } \\
\text { Range of breakpoints }\end{array}$ & $\begin{array}{c}0.5 \\
1 \\
0.25-2 \\
\end{array}$ & $\begin{array}{c}0.12-0.25 \\
>0.06 \text { to }<1\end{array}$ & $\begin{array}{c}0.06 \\
0.06 \\
0.06-0.25 \\
\end{array}$ \\
\hline Ampicillin & $\begin{array}{l}\text { CSLI/NCCLS } \\
\text { EMGM working group } \\
\text { Range of breakpoints }\end{array}$ & $\begin{array}{l}2 \\
2\end{array}$ & $\begin{array}{l}0.25-1 \\
0.25-1\end{array}$ & $\begin{array}{l}0.12 \\
0.12\end{array}$ \\
\hline Ceftriaxone & $\begin{array}{l}\text { CSLI/NCCLS } \\
\text { EMGM working group } \\
\text { Range of breakpoints }\end{array}$ & & & $\begin{array}{l}0.12 \\
0.12\end{array}$ \\
\hline Chloramphenicol & $\begin{array}{l}\text { CSLI/NCCLS } \\
\text { EMGM working group } \\
\text { Range of breakpoints }\end{array}$ & $\begin{array}{l}8 \\
8\end{array}$ & $\begin{array}{l}4 \\
4\end{array}$ & $\begin{array}{l}2 \\
2\end{array}$ \\
\hline
\end{tabular}

\section{Determining serogroups of $N$. meningitidis Reactives:}

- Latex agglutination reagent PASTOREX MENINGITIS BIORAD, Meningo A,B,C and Y-W135

- Group-specific anti-serums for serogroup A, $\mathrm{B}$ and $\mathrm{C}$ (horse), (CNRM).

- Group-specific (rabbit) antiserums for serogroup B, 29E, Y, W 135, X, Z (CNRM).

\section{Technique:}

Determining serogroups with latex agglutination test is done from culture cultivated 18-24 hours on Mueller- Hinton.

The ascertaining takes place on microscope slide.

When these group-specific serums are used to determine the serogroup of meningococci plates with deep holes are used with rectangular section.

The strains with the antiserums are tested with saline solution as well for occurrence of nonspecific agglutination.

- $3 \mathrm{mg}$ from the Mueller-Hinton medium is being used. Bacterial suspension with turbidity $\mathrm{Mc}$ Farland turbidity Standard 21 unit volume $(100 \mu 1)$ from the bacterial suspension is mixed with 1 unit volume of each antiserum.

It is shaken for 5 min. (shaker). The reading is executed on black background.

There are four options:

A/ agglutination with one anti-serum - it specifies the serogroup of the strain.

$\mathrm{B} /$ agglutination with a lot of antiserums, but without agglutination with saline solution - the strain is polyagglutinable! 
$\mathrm{C} /$ agglutination with a lot of serums and with saline solution - the strain is autoagglutinable.

$\mathrm{D} /$ there is no agglutination with the antiserums and with saline solution - the strain is nonagglutinable!

Determining serogroups by gene amplification for serogroups A, B, C, Y, W135 and $X$ with PCR reaction (TECHGEN 25X0.2) (3).

11. Confirmation of serogroup and species identification using real-time PCR. (4).

Principe of the reaction:

PCR is a reaction of repetition at 3 stages implemented in a sequence in one and the same test tube - thermal reactions. It is based on the technique of increase of amorces. The multiplication takes place in the two DNA chains.

A/ Stage of denaturation (separation) of nucleic acid. The stage corresponds to losing of the carbon connections between the nitrogen bases. It takes place at $94^{\circ} \mathrm{C}$.At the end of this stage both chains are separate (divided).

B/ Stage of hybridization (renaturation)b.

The progressive reduction of the temperature leads to hybridization of the oligonucleotides on the homologous fragments of the single DNA chain. The reaction is almost instant. These oligonucleotides will orientate the synthesis to the fragment of the DNA, which we are interested only if is present in the material. C/ Stage of amplification - implemented by DNA polymerase.

Oligonucleotides serve as fragments of DNA polymerase that will copy each of the two initial chains.. The newly-synthesized chain is extended (increased) in direction 5' -3 'and each new base is arranged at a place, complemented on the matrix base. The newly synthesized DNAs in turn after separation will become matrices and will fix the two fragments that will also be multiplied by DNA-polymerase.The specific of the PCR is based on the quality of the hybridization: primer-specific sequences.

A chain reaction takes place by repetition of cycles of separation, hybridization and amplification (multiplication) with the support of the DNA - polymerase polymerase chain reaction.

12. Antigen suspension preparation:

Dense suspension is prepared in $3 \mathrm{mg}$. buffered PBS IX. Inactivate it $30 \mathrm{~min}$ at $56^{\circ} \mathrm{C}$.
In another test tube adjust the inactivated antigen suspension up to 0.5 MacFarland in volume 3 mg. Distribute $100 \mu 1$ of each Suspension in 3 tubes? They are identical. Incubate them overnight at $45^{\circ} \mathrm{C}$.

Storage of the strains: Take with tampons enough volume of the culture $(1 / 4$ from the petri dish) in 2 cryo-tubes. Store at $-80^{\circ} \mathrm{C}$.

\section{Preparation of bacterial extract:}

Take (skim) with the help of tampons from the petri and make suspension in $700 \mu \mathrm{l}$ sterile distilled water.

Store at $-20^{\circ} \mathrm{C}$. It is used for PCR, MLST. It could be submitted instead of strains!!!

\section{SEROTYPING AND SEROSUBTYPING OF $N$. meningitidis. (5).}

Method:

Reaction of enzyme-linked immunosorbent assays (ELISA) using 6 Mbas antibodies for ascertaining of the serotype and 15 Mbas for ascertaining the serosubtype.

A/ Preparing dense suspension in $10 \mathrm{ml}$ PBS ;

$\mathrm{B} /$ Inactivation at $56^{\circ} \mathrm{C}$ for $30 \mathrm{~min}$. in water bath;

C/ Distribution of the suspension in $0.5 \mathrm{mg}$ in cryogenic tubes of $1.8 \mathrm{mg}$.

They are stored at $-20^{\circ} \mathrm{C}$.

D/ Preparation of antigen suspensions;

E/ Preparation of monoclonal antibodies (Mbas) marked with peroxidase and chromogenic substrate,

ELISA reaction

- $\quad$ sensitization

- $\quad$ drying the plates

- flushing

- specific reaction with Monoclonal antibodies (Mbas)

reading

15. Molecular typing with MLST

Principe: Comparing order of genes that code cytoplasmic proteins of the major metabolism of meningococci. Combining 7 alleles ascertains a Sequence Type $(\mathrm{ST})$ of a given strain. $(\mathbf{7 , 8 )}$.

\section{DISCUSSION}

The difficulties related to etiological diagnosis of meningococcal disease are due to:

-Demand for expensive media and diagnostic kits

-Lack of updated methodical instructions for laboratory diagnostics.

The diagnostic algorithm of bacterial meningitidis is in the center of the attention of:

World Health Organization

(WHO) 
characterization.html) laboratory experts and epidemiologists of the EU (Directions for monitoring and standardization of the diagnostic methods of bacterial meningitidis) as well as BULStar.

Table 3. Frequency of N. meningitidis, S. pneumoniae and H. influenzae, isolated from cerebrospinal fluid in Bulgarian Hospitals are showen

\begin{tabular}{|c|c|c|c|c|c|c|c|}
\hline \multirow{2}{*}{ Year } & \multirow{2}{*}{$\begin{array}{c}\text { Number of } \\
\text { positive samples }\end{array}$} & \multicolumn{2}{|c|}{ N. meningitidis } & \multicolumn{2}{c|}{ S. pneumoniae } & \multicolumn{2}{c|}{ H. influenzae } \\
\cline { 3 - 7 } & number of isolates & $\%$ & number of isolates & $\%$ & number of isolates & $\%$ \\
\hline 1999 & 231 & 13 & 5.5 & 57 & 24.7 & 0 & 0 \\
\hline 2000 & 292 & 16 & 5.5 & 32 & 10.9 & 24 & 8.2 \\
\hline 2001 & 113 & 17 & 15.5 & 40 & 35.4 & 12 & 10.6 \\
\hline 2002 & 95 & 8 & 8.4 & 32 & 33.7 & 16 & 16.8 \\
\hline 2003 & 121 & 15 & 12.4 & 34 & 28.1 & 10 & 8.3 \\
\hline 2004 & 194 & 12 & 6.2 & 30 & 15.5 & 9 & 4.6 \\
\hline 2005 & 188 & 18 & 9.6 & 44 & 23.4 & 14 & 7.4 \\
\hline 2006 & 199 & 17 & 8.5 & 61 & 30.7 & 13 & 6.5 \\
\hline 2007 & 174 & 14 & 8.0 & 44 & 25.3 & 18 & 10.3 \\
\hline 2008 & 139 & 20 & 14.4 & 39 & 28.1 & 11 & 7.9 \\
\hline
\end{tabular}

The prognosis and the survival of patients with meningococcal disease depend of the early exacte microbiological diagnosis and antibiotic therapy. It needs laboratory equipement, expensive media and diagnostics kits and training stuff.The diagnosis include conventional, as well as additional identification methods, as: automated systems for identification;

Serogrouping (N. meningitidis), Serotyping and Subserotyping of $N$. meningitidis isolates.

\section{REFERENCES}

1. Muhamed-Kher Taha, Jean-Michel Alonso, Mary Cafferkey, et al. Interlaboratory Comparison of PCR-Based Identification and Genogrouping of $N$. meningitidis. J. Clin. Microbiol. 2005, 43(1):144. DOI:10.1128/JCM.43.1.144-149, 2005.

2. Taha M. K., Giorgini D., Ducos-Galand M., Alonso J. M. Continuing diversification of $N$. meningitidis $\mathrm{W} 135$ as a primary cause of meningococcal disease after emergence of the serogroup in 2000. J. Clin. Microbiol. Sep: 42(9): 4158-63, 2004.

3. Muhamed-Kher Taha, Ala Eddine Deghmane, Eva Hong, Corinne Ruckly, Dario Giorgini.
Meningites

Bacteriennes: ApproachesBacteriologiques\&Moleculaires. Institut Pasteur 6-17 Decembre 2010. Travaux Pratiques, Centre National de Reference des Meningocoque, Unite des Infections bacteriennes Invasive.

4. Riou J. Y., Guibourdenche M. Donnees pratiques sur $N$. meningitidis: identification bacteriologique et serogroupage. "Feulletes de biologie», 1990 (n99).

5. Riou J. Y., Poolman J. T., Auriol J., Lomprez F., Guibourdenche M. Sero and subtyping of group B, C, Y and A meningococci isolated in France in 1988. Ann. Biol. Clin., 1990 (n100).

6. Riou J. Y., Guibourdenche M. Meningococcies: epidemiologie 1987-1992. Donnees actuelles. Med. Mal. Infect., 1992 (n118). 7. Riou J. Y., Guibourdenche M. Les infections meningococciques en France, 19881992. Ann. Inst. Pasteur/actualites, (n136), 1994.

7. Riou J. Y., Guibourdenche M. Les infections meningococciques en France, 1988-1992. Ann. Inst. Pasteur/actualites, 1994, (n136)

8. Maiden M. C., Bygraves J. A., Feil E., et al. Multilocus sequence typing a portable approach to the identification of clones within populations of pathogenic microorganisms. Proc Nat Acad Sci USA 95: 3140-3145, 1998. 